\title{
O papel dos fatores políticos na internacionalização de empresas: o caso da Energias de Portugal (EDP) no Brasil
}

\author{
The role of political factors in the internationalization of companies: the case of Energias de \\ Portugal (EDP) in Brazil
}

Carla Madalena Alves Fernandes ${ }^{1}$

Rodrigo Bandeira-de-Mello ${ }^{2}$

Pedro Pinto Zanni ${ }^{3}$

\section{Resumo}

Este estudo tem como objetivo analisar o papel dos fatores políticos e sua relação com os fatores mercadológicos no processo de internacionalização de empresas multinacionais. Este estudo de caso processual permite que a dinâmica do fenômeno seja analisada em três níveis: o ambiente nacional, setorial e organizacional. É realizada uma revisão teórica sobre a empresa multinacional e sobre o papel dos fatores políticos. Posteriormente, é descrito e analisado o processo de internacionalização de uma empresa portuguesa de capitais públicos, a - Energias de Portugal (EDP). Conclui-se que a posse de capacidades e recursos técnicos e de know-how para a entrada e consolidação da empresa no Brasil foram condições necessárias, mas não suficientes para viabilizar o processo de internacionalização da EDP no Brasil; e que a história da EDP no Brasil representa o caso de uma empresa oriunda de um país com estabilidade institucional que desenvolveu novas capacidades para lidar com o ambiente político e mitigar o risco.

Palavras-chave: Internacionalização. Estratégias políticas. Brasil.

\begin{abstract}
This study aims at analyzing the role of political factors and their relation to market factors in the internationalization process of multinational companies. This procedural case study allows the dynamics of this phenomenon to be analyzed in three levels: national, industrial, and organizational environments. A theoretical review on the multinational company and on the role of political factors is carried out. Subsequently, the internationalization process of a Portuguese company with public capital, Energias de Portugal (EDP), is described and analyzed. One concludes that the possession of abilities, technical resources, and know-how for the company to enter and consolidate in Brazil were needed conditions, but they were not enough to enable EDP's internationalization process in Brazil; and that EDP's history in Brazil represents the case of a company from a country with institutional stability which developed new abilities in order to deal with the political environment and to mitigate the risk.
\end{abstract}

Keywords: Internationalization. Political strategies. Brazil.

${ }^{1}$ Mestranda pela Fundação Getulio Vargas / EAESP; Pós-graduada em Gestão Financeira pelo ISG - Instituto Superior de Gestão (Lisboa, Portugal) e International MBA pela Universidade de Varsóvia (Varsóvia, Polônia). Endereço: Rua Itapeva, $474-11^{\circ}$ andar, Bela Vista, CEP 01331-000, São Paulo - SP, Brasil. E-mail: cmafsoares@hotmail.com

2 Professor Adjunto da Fundação Getulio Vargas / EAESP; Pós-doutorado na Paris-Dauphine; Líder da linha de pesquisa em Estratégia Empresarial do Programa de Mestrado e Doutorado em Administração de Empresas (FGV-EAESP). Endereço: Rua Itapeva, 474 - 11ํandar, Bela Vista, CEP 01331-000, São Paulo - SP, Brasil. E-mail: bandeira.demello@fgv.br

${ }^{3}$ Professor da Fundação Getúlio Vargas / EAESP; Doutorando e Mestre em Administração de Empresas (FGV-EAESP) com foco em Estratégia Empresarial. Endereço: Rua Itapeva, 135 - apto. 51, Vila Madalena, CEP 05442-010, São Paulo - SP, Brasil. E-mail: Pedro.Zanni@fgv.br 


\section{Introdução}

Apesar do crescente número de estudos de caso sobre processos de internacionalização de empresas encontrados na literatura, relativa pouca atenção tem sido dada à presença de fatores não mercadológicos e à sua influência, não só na definição de formas de entrada, como também no desenvolvimento e consolidação da estratégia das empresas multinacionais em mercados estrangeiros. Os estudos existentes focalizam-se na escolha do modo de entrada de empresas multinacionais e centram sua análise particularmente em como as empresas podem mitigar o risco político de expropriação quando governos do país alvo recorrem a mecanismos de reformas fiscais, reformas de regulação do setor ou impondo outras medidas de restrição de atividades de financiamento (HENISZ, 2000; FRYNAS, MELLAHI e PIGMAN, 2006).

$\mathrm{O}$ entendimento acerca de como ocorre o processo de relacionamento entre empresa multinacional e governo de origem além da escolha de entrada da empresa, mas durante seu processo de crescimento e consolidação (vírgula) ainda carece de estudos. A literatura existente privilegia estudos quantitativos que não conseguem capturar a dinâmica da relação empresa multinacional-país hospedeiro (HOLBURN e ZELNER, 2010).

Este estudo de caso visa fornecer insights sobre esse fenômeno a partir da utilização de um framework que relaciona os fatores relacionados ao mercado (market factors) com os fatores não relacionados ao mercado (nonmarket factors). Estes últimos são analisados em três níveis: nacional, setorial e organizacional. Assim, procura-se dar vida ao processo, analisando-se pormenorizadamente o papel dos fatores políticos na operação de uma empresa multinacional em um mercado estrangeiro. Investiga-se uma empresa portuguesa, a Eletricidade de Portugal, no Brasil. A escolha da empresa e de seu processo de internacionalização para o Brasil permite capturar a integridade do fenômeno nos níveis de análise escolhido. O Brasil é um dos países emergentes que tem atraído um crescente número de empresas multinacionais e este mercado, pela sua dimensão, proximidade cultural e taxas de crescimento não ficou alheio às ações de internacionalização de empresas portuguesas. Neste processo de internacionalização, que teve um forte impulso na década de 1990 (SILVA, 2005), participaram empresas dos setores de infraestrutura com participações do estado português (FERNANDES, SILVA e COSTA, 2003). Entre 1996 e 2001, Portugal foi o quinto país que mais realizou investimentos diretos no Brasil (FERNANDES, SILVA e COSTA, 2005), e estes representaram 42,3\% de todo o investimento estrangeiro direto realizado por Portugal no período (SILVA, 2005). Em 1998, com auge das privatizações no Brasil, os investimentos portugueses no país chegaram a $4 \%$ do PIB de Portugal (FERNANDES, SILVA e COSTA, 2003).

\section{Referencial teórico}

\section{Teorias da empresa multinacional}

O processo de internacionalização de empresas tem sido alvo de estudos que procuram descrever e explicar a dinâmica desse processo. Os primeiros estudos, desenvolvidos na década de 1960, tiveram a contribuição de Vernon (1966) com a Teoria do Ciclo de Vida do Mercado. Segundo Vernon, empresas que enfrentassem fases de maturidades nos mercados domésticos poderiam ampliar o ciclo de vida dos seus produtos entrando em mercados cujo nível de desenvolvimento estivesse numa fase inicial retirando vantagens comparativas das, já comprovadas, inovações dos seus produtos. Na década de 1970, as teorias comportamentais, cuja principal contribuição veio da escola nórdica de Uppsala com o Modelo de Uppsala ganharam força (JOHANSON e VAHLNE, 1977). Esse modelo estabelece uma escala de comprometimento da empresa com o mercado externo, em que a entrada e o investimento num mercado externo estão diretamente dependentes do grau de conhecimento do mercado e da "distância psíquica" percebida. As empresas privilegiam mercados, para início dos seus processos de internacionalização, em que fatores como língua, cultura e desenvolvimento econômico são semelhantes ao mercado de origem e, portanto, diminuem a distância 
psíquica. À medida que a experiência e conhecimento desses mercados aumentam, intensificam o nível de investimento e comprometimento.

Nas teorias com enfoque econômico têm principal relevo Hymer (1960), Buckley e Casson (1976) e Dunning (1988). Para justificar a razão de existência de empresas multinacionais, Hymer partiu de dois pontos fundamentais: (1) ao entrar num novo mercado estrangeiro, as empresas multinacionais necessitam construir barreiras contra as empresas concorrentes locais, pressupondo que estas se beneficiam de vantagens inerentes por exercerem atividades no seu próprio país. Ou seja, para superarem os ônus de serem estrangeiras, as Empresas Multinacionais (EMN) deverão ter vantagens competitivas superiores às concorrentes locais, como processos de ganhos de produtividade, controle de custos, ou know-how específico, que lhes permite uma diferenciação em relação aos seus concorrentes e o acesso ao mercado; (2) as EMN escolhem Investimento Estrangeiro Direto (IED) em detrimento de outras opções como licenciamento. A justificativa provém, segundo Hymer, de uma análise custo-benefício em que a opção IED se apresenta como a mais adequada com os objetivos estratégicos da matriz por duas razões: i) a EMN procura eliminar a concorrência no mercado local através da aquisição de empresas locais; ii) o controle direto apresenta-se como mais lucrativo face às dificuldades e custos associados em administrar um licenciamento. Buckley e Casson (1976), apoiados no conceito de custos de transação (COASE, 1937; WILLIAMSON, 1985), atribuem importância ao conceito de internalização para justificar a existência dos processos de internacionalização. As empresas procuram ultrapassar as imperfeições nos mercados criando mercados internos (integração vertical); e quando esses mercados extrapolam os limites das fronteiras geográficas verifica-se a existência de empresas multinacionais. Esses mercados podem abarcar bens físicos -produtos intermediários - ou ativos intangíveis como conhecimento, experiência, procedimentos, patentes.

Ainda dentro deste enfoque econômico, o paradigma eclético de Dunning (1988) tem por base três fatores para explicar a internacionalização de empresas: 1) Ownership efeitos de propriedade de ativos específicos da empresa, 2) Location, efeitos que o meio ambiente provoca nas competências da empresa e 3) Internalization, efeitos que decorrem da empresa garantir as atividades num outro país através dos seus próprios meios e não recorrendo a uma terceira entidade. Note-se que o terceiro fator do paradigma de Dunning, a internalization, está apoiado nas ideias propostas por Buckley e Casson (1976) para explicar os processos de internacionalização. Assim, Dunning oferece importante contribuição ao expandir a explicação anteriormente apresentada por Buckley e Cason, que restringia em grande parte seus argumentos para a existência das EMNs às vantagens de internalização. A dimensão location apontada por Dunning ganha destaque nos estudos desenvolvidos posteriormente por Porter (1990), que estuda as vantagens de empresas se instalarem nas regiões em que há concentração de empresa do mesmo setor. A essas concentrações é dado o nome de "aglomerados industriais" e as empresas que se instalam nestas regiões poderiam se beneficiar do conhecimento gerado localmente (pelo conjunto de empresas lá instaladas). Assim, Porter sugere que a empresa identifique esses aglomerados ao redor do mundo a fim de instalar ali suas bases.

Recentemente, a "visão baseada em recursos" ou RBV (resource based view), com base de inspiração nos trabalhos de Penrose (1959), colocou ênfase nos como fonte vantagem competitiva sustentável. Embora no meio acadêmico se discuta o incremento de sua contribuição, ela veio consolidar a relevância dos recursos e competências da empresa na persecução da sua estratégia internacional. A RBV foi especialmente difundida por meio do trabalho de Barney (1991), que defende que a vantagem da empresa decorre da exploração de seus recursos valiosos, raros e de imitação dispendiosa. Note-se que tal argumento guarda relação com o conceito "ativos especiais", proposto por Caves (1971) e o conceito de "ownership", proposto por Dunning (1988).

\section{O papel dos fatores políticos}

Apesar da multiplicidade de abordagens e lentes teóricas para explicar os processos de internacionalização e vantagem competitiva de empresas, um dos fatores negligenciados pela literatura é o papel dos fatores 
políticos. Se por um lado os fatores de mercado são contemplados de forma abrangente e diversas lentes são utilizadas pelas teorias do processo de internacionalização, elas não garantem espaço relevante para as relações de não mercado (nonmarket) existentes entre a esfera empresarial e a política. Os modelos de gestão em negócios internacionais têm se baseado principalmente na perspectiva que privilegia a análise das interdependências entre as empresas e seus ambientes econômicos, enquanto pouca atenção é dada às teorias que explicam as interdependências entre as empresas e seus ambientes políticos (RING, LENWAY e GOVEKAR, 1990).

A literatura sobre estratégias políticas, ou non-market, procura explicar como as empresas desenvolvem mecanismos de acesso aos decisores políticos e influenciar o próprio processo político (HILLMAN, KEIM e SCHULER, 2004). Conseguir vantagens competitivas através do uso de recursos políticos é uma importante estratégia não mercadológica ou non-market startegy na medida em que as empresas procuram se beneficiar de políticas cujos resultados são assimétricos para as empresas (SCHULER, REHBEIN e CRAMER, 2002). De uma forma geral, essas estratégias envolvem ações como lobbying, doações para campanhas eleitorais, apoio às causas públicas (advocay advertizing), mobilização dos eleitores na direção de atuação política (constituency building), construção de coalizões e serviços prestados por dirigentes das empresas atuando em cargos públicos (HILLMAN e HITT, 1999). A literatura existente sobre estratégias não mercadológicas admite o benefício indireto individual por parte das empresas (HILLMAN, KEIM e SCHULER, 2004), tais como efeitos assimétricos da regulação (SHAFFER, 1995; MCWILLIAMS, VAN FLEET e CORY, 2002) e a proteção contra concorrência internacional (SCHULER, 1996). Outros estudos apontam igualmente para relações diretas de membros dos Conselhos de Administração de empresas que são indicados para executar cargos públicos (LESTER, HILLMAN, ZARDKOOHI et al., 2008).

Os fatores políticos são especialmente importantes no contexto de negócios internacionais (HENISZ e WILLIAMSON, 1999; HOLBURN e ZELNER, 2010). Isso porque as empresas internacionais operam sob uma variedade de regimes políticos que impactam o modo no qual as firmas entram, operam e saem dos mercados estrangeiros (BODDEWIN e BREWER 1994, RING, LENWAY e GOVEKAR, 1990). Nesse contexto, tem-se que as empresas frequentemente devem negociar e manter um domínio no seu ambiente não mercadológico (nonmarket), especialmente no que tange à dimensão política deste ambiente. Um dos primeiros esforços para integrar a dimensão política às teorias de International Business (IB) foi apresentado por Boddewyn (1988), que propõe a expansão do paradigma eclético de Dunning (1988), de forma a incluir a dimensão política nas considerações sobre as vantagens de propriedade (ownership), internalização e localização. Note-se que Boddewyn (1988) reconhece que Dunning e outros se referiam explicitamente à intervenções governamentais de vários tipos, mas as tratavam como fatores dados, essencialmente externos e sobre os quais a empresa multinacional só deveria reagir, e não buscar influenciar. Boddewyn (1988) propõe, portanto, que se eleve a análise das empresas multinacionais de uma perspectiva puramente econômica para uma análise mais político-econômica e até, sociocultural, de forma que os fatores não mercadológicos não sejam associados simplesmente ao risco (como as frequentes referências aos riscos políticos), mas também às oportunidades (por exemplo, oportunidades políticas). Esse argumento é reforçado em recente estudo de Holburn e Zelner (2010) cujas evidências mostram que a habilidade em lidar com o risco político de países pelas empresas multinacionais depende da sua capacidade aprendida em seu país de origem.

A habilidade de gerenciar as relações com os governos (e instituições em geral) dos países hospedeiros é especialmente crítica em alguns setores (HENISZ, 2003). Isso porque certas indústrias apresentam um maior grau de envolvimento com o governo porque a sociedade espera que seus proprietários e gestores considerem, além dos objetivos de privados (ou seja, a maximização do lucro), os objetivos públicos (como o crescimento econômico do país e o impacto na sociedade). Entre esses setores tipicamente caracterizados como de forte interesse público estão a geração e distribuição de energia, saneamento, finanças, extração de recursos naturais e transporte. Nessas indústrias, portanto, é especialmente importante a utilização, por parte das empresas, de estratégias de influência e lobbying (HENISZ, 2003). Especificamente sobre o setor de energia, Henisz (2003) aponta a necessidade de a empresa multinacional estar atenta à estrutura das agências regulatórias do país (incluindo as relações entre os atores regulatórios e políticos), o processo pelo quais 
novas empresas entram no mercado, o modelo de venda de energia, as garantias de que terão condições de recuperar seus investimentos, as práticas operacionais entre outros aspectos críticos e bastante relacionados a questões políticas e regulatórias.

Independe do setor de atuação das EMNs, as particularidades institucionais de cada país influenciam significativamente a forma como as empresas interagem com os governos locais nos processos de procurar influenciar políticas públicas (HILLMAN e KEIM, 1995). Frequentemente, as atividades políticas das subsidiárias de empresas multinacionais diferem daquelas adotadas pelas suas matrizes. Isto porque as interações das subsidiárias com os países hospedeiros são caracterizadas por diferentes níveis de particularização (associados às características de cada subsidiária) e coordenação central (apoiada nos objetivos gerais da EMN) (BLUMENTRITT e NIGH, 2002). Além disso, as estratégias políticas das subsidiárias são afetadas não só por pressões institucionais das suas matrizes, mas também dos países hospedeiros (HILLMAN e WAN, 2005).

Com uma perspectiva inovadora sobre a importância dos fatores não mercadológicos em processos de entrada em novos países, Frynas, Mellahi e Pigman (2006) analisam a importância dos recursos políticos na criação das vantagens do pioneiro (first mover advantages) em negócios internacionais. Os autores reforçam que as dimensões não mercadológicas têm sido negligenciadas pelos pesquisadores também no que tange à compreensão e explicação dos benefícios do pioneiro. Por meio de três estudos de caso realizados em diferentes setores e países, Frynas Mellahi e Pigman (2006) mostram diferentes relações causais entre os recursos políticos e as vantagens de pioneiro e apontam como estratégias não mercadológicas podem ser utilizadas de forma bem-sucedida pelo primeiro a entrar em um mercado internacional, assim como podem também ser utilizadas por entrantes tardios para neutralizar as vantagens do pioneiro.

Em alguns casos, as estratégias políticas das empresas em suas operações internacionais acabam mobilizando de forma tão significativa os governos dos países envolvidos que questões concorrenciais entre empresas acabam se tornando disputas comerciais entre países. Em caso bem documentado por Baron (1997), duas grandes empresas do segmento fotográfico vinham enfrentando grande dificuldade para ampliar sua participação de mercado no país de origem do seu maior rival e se utilizaram de estratégias políticas para conseguir maior penetração em mercados internacionais. Após utilizarem-se ao longo dos anos de diferentes estratégias mercadológicas que pudessem melhorar a sua posição nesses mercados-alvo, reconheceram a necessidade de atuarem juntamente com os governos dos países hospedeiros para derrubar práticas de truste de seus concorrentes locais. Assim, por se tratar de ações antitruste, estas EMNs conseguiram inclusive apoio dos governos dos seus países de origem para pressionar os governos dos países hospedeiros a proteger os interesses comerciais destas empresas. $\mathrm{O}$ caso ilustra claramente como duas concorrentes, utilizando-se de estratégias e recursos políticos, transformaram um disputa entre empresas em uma questão entre países, o que aumentou muito suas chances de sucesso.

Embora até aqui tenha sido apontado que a empresa multinacional tem, de forma geral, desvantagens em relação aos seus concorrentes domésticos por não estar inserida no contexto político e institucional do país hospedeiro, Henisz (2003) aponta que ela também pode ter algumas vantagens. Isto porque as empresas multinacionais geralmente: i) são maiores e mais rentáveis que as empresas locais, o que permite maiores investimentos (um importante argumento em processos de lobbying) e ii) são mais estabelecidas em seus setores, o que dá a elas mais legitimidade em negociações políticas. É importante destacar o interessante alerta que Sun, Mellahi e Thun (2010) fazem à amplamente aceita valorização dos recursos não mercadológicos na atuação de empresas multinacionais em seus países hospedeiros (especificamente em países emergentes) com o intuito de superar em parte o custo de ser estrangeiro, ou liability of foreignnes. Ao analisar a atuação de grandes empresas multinacionais do setor automobilístico na China no período de 1980 até o ano 2000, os autores mostram como essas empresas bem relacionadas politicamente obtiveram vantagens sobre seus competidores em um primeiro momento, mas como o valor destas conexões em alguns casos não só perdeu valor ao longo do tempo como até se tornaram um passivo após mudanças políticas. Note-se que os autores não negam a importância dos fatores não mercadológicos, mas apenas fazem um 
alerta ao mostrar que o valor dos fatores políticos pode mudar ao longo do tempo e que as relações próximas com instituições políticas que podiam ser valiosas em um primeiro estágio de competição podem se tornar um peso.

A utilização de estratégias políticas por empresas multinacionais vem sendo especialmente estudada em países emergentes, em que as instituições de forma geral têm um comportamento menos estável e, principalmente, mais corruptível se comparadas às dos países desenvolvidos. Nesse contexto, Rodriguez, Uhlenbruck e Eden (2005) e Luo (2006) analisam especificamente os desafios para a execução de estratégias políticas por parte das empresas em seus processos de entrada em países que possuem governos corruptos (ou percebidos como corruptos). Observa-se que, quanto maior for a legitimidade da EMN, mais ela terá condições de buscar apoio de outras instituições a fim de protegê-la da corrupção geral. Consequentemente, maior será sua liberdade para implementar estratégias tanto de mercado como não mercadológicas (RODRIGUEZ, UHLENBRUCK e EDEN, 2005). Nota-se, entretanto, que a forma de atuação política das empresas multinacionais que atuam em países corruptos varia de acordo com o perfil destas empresas e de quanto valorizam questões éticas. Luo (2006) identifica que, quando as EMNs que têm foco na ética atuam nestes países, tendem a ter uma relação mais impessoal e mais distante (arm's lenght) ao estabelecer relações e negociar com o governo. Ao mesmo tempo, as contribuições filantrópicas dessas empresas tende a diminuir. Por outro lado, aquelas EMNs que focam menos em questões éticas têm uma propensão maior para utilizar conexões sociais ao negociar com o governo local. Uma das estratégias que têm facilitado o processo de entrada de EMNs em países corruptos é o estabelecimento de alianças com parceiros locais, o que tende a aumentar a legitimidade do novo entrante e facilitar o estabelecimento de estratégias políticas (HILLMAN e KEIM, 1995).

\section{Metodologia}

Esta pesquisa foi desenvolvida a partir de um estudo de caso único, processual, de natureza qualitativa (YIN 2005; EISENHARDT 1989; EISENHARDT e GRAEBNER 2007), tendo sido conduzido de forma a permitir a construção e o refinamento de teorias, além da geração de insights (ZANNI, MORAES e MARIOTTO 2011). A empresa objeto deste estudo, a Energias de Portugal (EDP), se apresentou como um caso interessante, pois está incluída no conjunto de empresas portuguesas, no qual se incluem a Portugal Telecom, a Cimpor (atua no segmento de cimento) e a Brisa (atua na gestão de autoestradas), que aproveitaram as potencialidades de uma conjuntura baseada em dois aspectos convergentes: por um lado, a política do governo português em promover a internacionalização da economia coincidindo com o período de privatizações no Brasil; e, por outro, o interesse e as estratégias dos principais grupos empresariais em iniciarem o processo de internacionalização. Foi através das ações e vontades coincidentes dos dois países, Portugal (através da promoção da internacionalização das empresas) e Brasil, através do processo de privatizações (as privatizações realizadas tiveram um papel ativo na captação de IED neste país), que foi possível a entrada significativa de algumas das principais empresas portuguesas no mercado brasileiro.

O caso da EDP no Brasil tornou possível a análise do papel dos recursos políticos no processo de entrada e de operação de empresa estrangeira em um mercado local. O caso também é interessante teoricamente, pois propicia a análise dos recursos empregados pela empresa em três níveis: o nacional, o setorial e o organizacional. A literatura sobre estratégia política das corporações aponta a importância do nível de abrangência das questões políticas (issues) endereçadas pela empresa na definição das estratégias políticas (BONARDI, HILLMAN e KEIM, 2005). As estratégias políticas e seus efeitos são influenciados por características no mercado político nos âmbitos regulatório e legislativo do país, no âmbito setorial, e características da firma (BONARDI, HOLBURN e BERGH, 2006). Empiricamente, esses três níveis são analiticamente relevantes à medida que abrangem grande parte do escopo de atuação política da empresa. A separação analítica permite ainda analisar a interação entre os três níveis e entre cada nível e a estratégia de internacionalização. 
O recorte temporal inclui a história da empresa no Brasil desde 1996, ano da sua entrada neste mercado, identificando as fases de desenvolvimento da sua estratégia de internacionalização, até 2010. Foram utilizadas apenas fontes de dados secundárias. O website da empresa foi utilizado para coleta de informação interna como histórico, estrutura acionista, estrutura organizacional, atividades desenvolvidas e estratégia delineada. Foram ainda consultados relatórios de administração e financeiros da empresa que contemplam o período em análise de 1996 a 2009. A coleta foi complementada com artigos e informações publicadas na imprensa, obtidas de maneira sistemática pelo Emerging Markets Information Service.

As análises dos dados foram feitas de forma a atenuar a subjetividade do pesquisador. Apesar de ser uma pesquisa qualitativa, os resultados não visam interpretar o fenômeno a partir do ponto de vista de um determinado grupo envolvido. Múltiplas fontes permitiram reconstituir o processo de entrada da empresa no Brasil de forma robusta e objetiva. Além disso, os pesquisadores analisaram os dados de forma independente, o que permitiu checar as análises de cada um. Os dados foram organizados temporalmente e ao longo de categorias de análise a partir de uma categorização simples para que prováveis associações pudessem ser inferidas. O framework (framework) analítico contempla as seguintes categorias: a) fatores baseados no mercado (market): são competências e recursos da empresa que lhe conferem vantagens comparativas em relação a seus concorrentes (BARNEY, 1991), tais como a combinação de equipe, recursos financeiros e timing dos investimentos; b) fatores políticos, não baseados no mercado (nonmarket): referemse a elementos do ambiente externo e interno à empresa que não podem ser transacionados em mercados de fatores ou de produtos. Os fatores políticos estão organizados em dois níveis no ambiente externo, nacional e setorial, e referem-se às características do ambiente institucional político: legislação, regulação, e acordos bilaterais. No ambiente interno, no nível organizacional, recursos políticos da firma permitem adoção de estratégias de pressão e influência que garantem à firma tratamento preferencial pelo governo, ganhos assimétricos de novas legislações e acesso aos recursos do país (FRYNAS, MELLAHI e PIGMAN, 2006; WAN, 2005).

\section{Análise dos Resultados}

\section{A EDP}

A EDP foi constituída em 1976 como resultado da nacionalização e fusão das principais empresas do setor elétrico português que se seguiu à revolução democrática ocorrida em Portugal após a queda do regime ditatorial de Salazar. A EDP foi durante a década de 1980 uma empresa nacional e verticalizada, responsável pela produção e distribuição de 95\% da energia elétrica de Portugal. Em 1991, o governo português decidiu alterar o estatuto jurídico da EDP, de Empresa Pública para Sociedade Anônima. Seguindo-se em 1994, uma profunda reestruturação, quando foi constituído o Grupo EDP. Em Junho de 1997 ocorreu a primeira fase de privatização da EDP, sendo alienados $30 \%$ do capital. Posteriormente, seguiram-se cinco fases de privatização: duas em 1998, e nos anos seguintes: 2000, 2004 e 2005. A Tabela 1 mostra que o Estado Português e outros entes públicos detêm uma participação minoritária, mas continuam a ser os principais acionistas cuja posição é reforçada por uma golden share. A PARPÚBLICA é uma sociedade gestora de participações sociais de capitais exclusivamente públicos que detém cerca de $21 \%$ das ações, estando os restantes $79 \%$ do capital distribuídos por diversos acionistas privados. 
Tabela 1

\section{Estrutura acionária}

\begin{tabular}{|c|c|c|}
\hline Acionista & \% Capital & \% Votos Exercitáveis \\
\hline PARPÚBLICA - Participações Públicas & $20,05 \%$ & $20,24 \%$ \\
\hline IBERDROLA - Participações, SGPS & $6,79 \%$ & $5,00 \%$ \\
\hline Caixa Geral de Depósitos & $5,66 \%$ & $5,45 \%$ \\
\hline Caja de Ahorros de Asturias & $5,01 \%$ & $5,00 \%$ \\
\hline José de Mello - Soc. Gestora de Participações \\
Sociais & $4,82 \%$ & $4,10 \%$ \\
\hline Sanfora SARL & $4,06 \%$ & $3,86 \%$ \\
\hline BlackRock, Inc. & $3,83 \%$ & $3,40 \%$ \\
\hline Grupo BCP + Fundo de Pensões do Grupo BCP & $3,36 \%$ & $3,06 \%$ \\
\hline Banco Espirito Santo, SA & $3,04 \%$ & $2,26 \%$ \\
\hline Sonatrach & $2,23 \%$ & \\
\hline EDP (ações próprias) & $0,94 \%$ & $40,20 \%$ \\
\hline Acionistas restantes & $100 \%$ & \\
\hline Total & & \\
\hline Fan & & \\
\hline
\end{tabular}

Fonte: Relatório da Diretoria (2009).

A EDP era, em 2010, um dos maiores grupos econômicos portugueses, a maior empresa industrial de Portugal, e o maior produtor de eletricidade, com produção de $80 \%$ e distribuição de $99 \%$ da eletricidade em Portugal. Em nível do mercado europeu, a EDP é o $3^{\circ}$ maior operador ibérico no setor de energia eólica e a $13^{\mathrm{a}}$ maior empresa de eletricidade (SIGARDO, 2010). Porém, analisando histórico no website da empresa, há dez anos a EDP era uma empresa regulada e cujas operações estavam limitadas ao mercado português. Com essa postura, não só o crescimento da empresa estava limitado, como estaria condenada a perder mercado com a crescente liberalização do mercado ibérico. A estratégia adotada seguiu dois eixos de estratégicos: no mercado nacional fomentando a eficiência e a sua competitividade e num segundo eixo apostando na internacionalização e entrada em novos mercados.

De acordo com o histórico da empresa descrito no seu site, os primeiros passos na internacionalização da EDP ocorreram em 1996. O Brasil foi o primeiro mercado escolhido para iniciar o processo de internacionalização, uma vez que era considerado como uma opção natural. A escolha justifica-se tanto pelas afinidades socioculturais e menor distância psíquica, aliada ao potencial de crescimento do mercado brasileiro e as dificuldades encontradas no Mercado Único Europeu, como também pelas motivações decorrentes do novo enquadramento institucional das relações Portugal-Brasil. No mercado brasileiro, a EDP 
apostou inicialmente no negócio da distribuição e foi alargando a sua área de atuação aos negócios de geração e comercialização de energia elétrica através da EDP - Energias do Brasil. O segundo passo no processo de internacionalização foi dado no mercado Espanhol. A Espanha, dada a proximidade geográfica, é a extensão natural do mercado doméstico português, possibilitando obter a dimensão necessária para que a EDP se afirmasse como principal player do mercado ibérico. A EDP passou a desenvolver a sua atividade principal no setor de energia na Península Ibérica antecipando o MIBEL - Mercado Ibérico de Eletricidade. O MIBEL constituiu uma iniciativa conjunta dos governos português e espanhol passando a ser possível, a qualquer consumidor no espaço ibérico, adquirir energia eléctrica, num regime de livre concorrência, a qualquer produtor ou comercializador de Portugal ou Espanha. Desde 2004, prosseguindo uma estratégia de diversificação do seu portfólio, a empresa passou a estar presente no negócio de gás, através da EDP Gás, tornando-se o segundo maior operador de gás tanto em Portugal como em Espanha. Em 2006, a EDP afirmou-se no negócio das energias renováveis, tendo 35\% da sua eletricidade gerada a partir dessas fontes. Recentemente, a EDP lançou-se em novos mercados, tendo entrado nos Estados Unidos da América, através da compra da Horizon Wind Energy, tornando-se assim o $4^{\circ}$ player mundial de energia eólica.

\section{A Internacionalização para o mercado brasileiro}

O modelo seguido pela EDP no processo de internacionalização no Brasil dá ênfase a áreas onde a empresa tem competências críticas e vantagens competitivas, aliado a um permanente diálogo com as autoridades locais. A EDP procurou ainda obter vantagens de uma padronização global, centralizando funções em que há economias de escala e definindo, quando possível, processos de negócios comuns. O Brasil é considerado o país de "grandes desafios" pelos empresários portugueses: as oportunidades são muitas apesar da turbulência política, resultante dos escândalos de corrupção e de clientelismo que atingem o Governo Federal e a classe política em geral. A escolha do Brasil, pela EDP, justifica-se pelas oportunidades abertas pelos programas de privatização das empresas brasileiras, pelo suporte recebido por parte dos governos português e brasileiro e por a empresa considerar que detém vantagens comparativas para operar neste mercado. Por outro lado, este mercado apresentava desafios a superar como a dimensão do país, gestão dos riscos cambial, regulatório e econômico e gestão das especificidades locais e culturais.

O percurso da EDP no mercado Brasileiro é caracterizado por quatro fases: (1) entrada em 1996 no segmento de negócio da distribuição e pela compra de participação no capital da CERJ; (2) consolidação, entre 2000 e 2003, reforçando o negócio da distribuição e alargando a sua área de atuação aos negócios da geração e comercialização; (3) reestruturação do portfólio, durante período os anos 2003 e 2005, cujo objetivo foi implantar um modelo diferenciado de gestão readequando a organização, os objetivos, os processos e a cultura corporativa; e (4) a última fase contemplada neste estudo, expansão autossustentável, que se iniciou no ano de $2005 \mathrm{com}$ a entrada da empresa no negócio de energias renováveis. A análise mais detalhada das atividades da empresa pode ser observada no quadro anexo. Em 2010, a EDP no Brasil é uma holding que detém investimentos no setor de energia elétrica, consolidando ativos de geração, distribuição e comercialização. A organização da empresa por segmento de negócio encontra-se detalhada na Tabela 2. 
Tabela 2

\section{Empresas participadas no Brasil por segmento de negócio}

\begin{tabular}{|c|c|c|c|}
\hline $\begin{array}{l}\text { Segmento } \\
\text { Negócio }\end{array}$ & Empresa & Participação & Atividade \\
\hline \multirow[t]{4}{*}{ Geração } & Energest & $100 \%$ & $\begin{array}{c}\text { Criada no âmbito do processo de desverticalização } \\
\text { das empresas Escelsa e Enersul. }\end{array}$ \\
\hline & $\begin{array}{l}\text { Investco } \\
\text { (Lajeado) }\end{array}$ & $73 \%$ & $\begin{array}{l}\text { Opera e mantém a hidroelétrica do Lajeado, no rio } \\
\text { Tocantins, estado Tocantins com potência total de } \\
\qquad 902,5 \mathrm{MW} .\end{array}$ \\
\hline & Enerpeixe & $60 \%$ & $\begin{array}{c}\text { Participação com } 60 \% \text { do capital na usina } \\
\text { hidroelétrica Peixe Angical, localizada no Rio } \\
\text { Tocantins, em parceria com Furnas hidroelétrica. }\end{array}$ \\
\hline & Energia Pecém & $50 \%$ & $\begin{array}{l}\text { Fruto de uma parceira 50/50 entre a MPX e a } \\
\text { Energias do Brasil, é uma usina termelétrica a } \\
\text { carvão de } 720 \mathrm{MW} \text { de capacidade instalada. }\end{array}$ \\
\hline \multirow[t]{2}{*}{ Distribuição } & EDP Bandeirante & $100 \%$ & $\begin{array}{l}\text { Atende uma população de 4,4 milhões de } \\
\text { habitantes nas regiões do Alto Tietê, Vale do } \\
\text { Paraíba e Litoral Norte de São Paulo }\end{array}$ \\
\hline & EDP Escelsa & $100 \%$ & $\begin{array}{c}\text { Atende uma população de 3,2 milhões de } \\
\text { habitantes em } 70 \text { das } 78 \text { cidades do Espírito } \\
\text { Santo. }\end{array}$ \\
\hline Comercialização & Enertrade & $100 \%$ & $\begin{array}{l}\text { Responsável pelas atividades de comercialização } \\
\text { da EDP no Brasil, prestando serviços de mercado } \\
\text { livre, dentro e fora das áreas de concessão. }\end{array}$ \\
\hline
\end{tabular}

Fonte: Site EDP.

\section{Os fatores políticos}

Nesta seção analisa-se o papel dos fatores políticos no processo de internacionalização da empresa EDP no Brasil. Procuram-se identificar associações entre fatores baseados no mercado (market) e os fatores políticos (non-market). A Tabela 3 sintetiza e descreve a associação entre esses dois fatores ao longo do tempo. Para o fator político, os dados foram organizados em três níveis, nacional, setorial, e organizacional. Possíveis associações indicam que de alguma forma fatores políticos contribuíram para aumentar a competitividade e mitigar os riscos das operações desenvolvidas pela EDP no mercado Brasileiro. 
Tabela 3

\section{Influência de fatores mercadológicos e não mercadológicos no processo de internacionalização da EDP}

\begin{tabular}{|c|c|c|c|c|c|}
\hline & 1995 & 2000 & 2003 & 2005 \\
\hline & & Entrada & Consolidação & $\begin{array}{l}\text { Reorganização do } \\
\text { Portfólio }\end{array}$ & $\begin{array}{c}\text { Expansão } \\
\text { Autossustentável }\end{array}$ \\
\hline \multicolumn{2}{|c|}{ 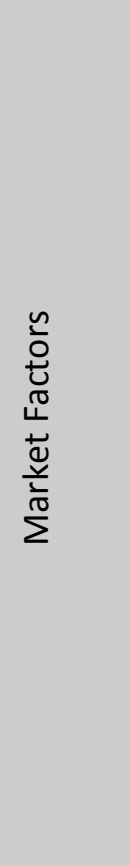 } & $\begin{array}{l}1995 \\
\text { Compra de 21\% da } \\
\text { CERJ } \\
\text { (Distribuidora no RJ) } \\
1997 \\
\text { Lajeado } \\
1998 \\
\text { Aquisição 17\% da } \\
\text { Bandeirante } \\
1999 \\
\text { Aquisição participação } \\
\text { indireta na Escelsa e } \\
\text { Enersul }\end{array}$ & $\begin{array}{l}2001 \\
\text { Criação da EDP Brasil } \\
\text { - OPA e Cisão da } \\
\text { Bandeirante } \\
\text { - Início da Fafen- } \\
\text { Central } \\
\text { termoelétrica na } \\
\text { Bahia } \\
\text { - Aquisição de 95\% } \\
\text { do projeto hídrico } \\
\text { Peixe Angical } \\
2002 \\
\text { Aquisição controle da } \\
\text { Escesa e Enersul }\end{array}$ & $\begin{array}{l}2003 \\
\text { Retomada das obras } \\
\text { de Peixe Angical } \\
2004 \\
\text { Venda da Fafen para } \\
\text { Petrobrás } \\
2005 \\
\text { - Conclusão do } \\
\text { processo de } \\
\text { reestruturação } \\
\text { societária } \\
\text { - Desverticalização } \\
\text { dos ativos, } \\
\text { segregação dos } \\
\text { negócios geração } \\
\text { e distribuição }\end{array}$ & $\begin{array}{l}2005 \\
\text { IPO das Energias do } \\
\text { Brasil } \\
2007 \\
\text { Investimento numa } \\
\text { central a carvão } \\
\mathbf{2 0 0 8} \\
\text { - Expansão para as } \\
\text { renováveis } \\
\text { - Transferência do } \\
\text { controle } \\
\text { societário da } \\
\text { Enersul para } \\
\text { Grupo Rede }\end{array}$ \\
\hline \multirow{2}{*}{ 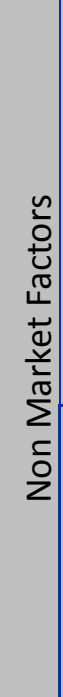 } & $\begin{array}{l}\bar{\pi} \\
\frac{1}{0} \\
. \frac{0}{U} \\
\frac{\pi}{z}\end{array}$ & $\begin{array}{l}\text { - Suporte do governo } \\
\text { brasileiro e } \\
\text { português } \\
\text { - Oportunidades } \\
\text { abertas pelos } \\
\text { programas de } \\
\text { privatização do } \\
\text { Brasil }\end{array}$ & $\begin{array}{l}\text { Governo brasileiro } \\
\text { demonstra intenção } \\
\text { de implementar um } \\
\text { ambiente que em } \\
\text { termos de regulação } \\
\text { do setor elétrico seja } \\
\text { estável e transparente }\end{array}$ & $\begin{array}{l}2003 \\
\text { Reforço da ligação } \\
\text { entre agências } \\
\text { econômicas e rede } \\
\text { diplomática para } \\
\text { promoção externa da } \\
\text { economia portuguesa }\end{array}$ & $\begin{array}{l}\text { Fórum Brasil 2005: } \\
\text { Prossecução, pelo } \\
\text { Estado Português de } \\
\text { política de diplomacia } \\
\text { econômica }\end{array}$ \\
\hline & $\begin{array}{l}\overline{.0} \\
\overline{2} \\
\stackrel{0}{0} \\
\sim\end{array}$ & $\begin{array}{l}\text { Processo } \\
\text { desestatização setor } \\
\text { elétrico paulista: } \\
\text { Aquisição da } \\
\text { Bandeirante }\end{array}$ & $\begin{array}{l}\text { Falta de definição de } \\
\text { um quadro de } \\
\text { regulação para o setor } \\
\text { elétrico leva a } \\
\text { adiamento do projeto } \\
\text { hídrico Peixe Angical }\end{array}$ & $\begin{array}{l}\text { Organização e } \\
\text { regulação setor } \\
\text { elétrico brasileiro } \\
\text { CPI Enersul - Reajuste } \\
\text { tarifário }\end{array}$ & $\begin{array}{l}\text { Enersul: Patrocínio a } \\
\text { magistrados }\end{array}$ \\
\hline
\end{tabular}




\begin{tabular}{|c|c|c|c|c|c|}
\hline 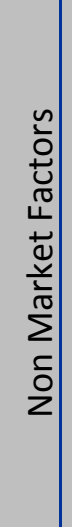 & 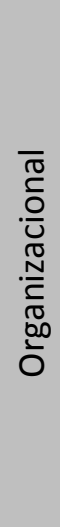 & $\begin{array}{l}\text { Controle da EDP } \\
\text { Portugal pelo Estado } \\
\text { Português - maior } \\
\text { acionista com } 20 \% \text { de } \\
\text { participação. } \\
\text { Golden Share: prevê } \\
\text { direitos especiais do } \\
\text { estado na empresa. }\end{array}$ & $\begin{array}{l}\text { Parceria com } \\
\text { Petrobras - Fafen }\end{array}$ & $\begin{array}{l}\text { Obtenção } \\
\text { financiamento BNDES } \\
\text { e consequente } \\
\text { retomada das obras } \\
\text { de Peixe Angical. } \\
\text { Novo Conselho de } \\
\text { Administração: } \\
\text { entrada de } 2 \\
\text { conselheiros } \\
\text { independentes }\end{array}$ & $\begin{array}{l}\text { Parceria com a MPX } \\
\text { Mineração } \\
\text { investimento na } \\
\text { central a carvão } \\
\text { Parceria com } \\
\text { Eletronorte } \\
\text { (construção de } \\
\text { hidroelétricas) } \\
\text { Parceria com } \\
\text { Petrobras ampliar } \\
\text { parque gerador Brasil }\end{array}$ \\
\hline
\end{tabular}

Fonte: elaborada pelos autores.

A influência de cada um dos três níveis do ambiente político é diferente ao longo da linha do tempo. Se, no início, os recursos disponíveis no nível nacional foram cruciais para a internacionalização da empresa, os dois outros níveis, setorial e organizacional, foram os que asseguraram o seu crescimento local. Nos últimos anos verifica-se que a principal força da EDP foram as parcerias com empresas estatais que continuam a garantir a expansão no setor de negócio de geração de energia. As próximas seções analisam alguns eventos importantes nos três níveis de análise.

\section{Nível Nacional - Relações com os estados português e brasileiro}

O estado português adotou uma política de incentivo e auxílio nos processos de internacionalização das empresas portuguesas, sendo prova disso os apoios prestados quer na vertente exportação, quer na vertente de investimento direto português no estrangeiro (SILVA, 2005). Como forma de projetar imagem da economia portuguesa e de um novo Portugal, têm sido desenvolvidas, com difusão em nível internacional, campanhas de comunicação para construir um novo currículo para Portugal em benefício das empresas portuguesas e reforçando a sua posição internacional. Numa vertente mais próxima do objeto do caso, a Agência para o Investimento e Comércio Externo de Portugal (AICEP) tem desenvolvido e executado políticas estruturantes e de apoio à internacionalização da economia portuguesa: (1) apoiando na definição e implantação de estratégias de abordagem dos mercados externos (adequação dos produtos aos mercados, análise da concorrência, informação econômica e regulamentar, estratégias de marketing, etc.), (2) prestando serviços de informação como divulgação de oportunidades de negócio, identificação de potenciais clientes estrangeiros, (3) disponibilizando informação técnica ou comercial sobre procedimentos relativos ao comércio internacional e (4) promovendo o acesso a programas comunitários e a fontes de financiamento multilateral. A integração das representações da AICEP na rede diplomática, em 2005, com a inclusão de um conselheiro comercial nas embaixadas e consulados, é um modelo que pretende pôr os diplomatas a fazer a promoção externa da economia portuguesa.

O esforço de cooperação estratégica entre Brasil e Portugal tem sido revelado ao longo das diversas cúpulas realizadas, onde acordos nas áreas econômicas, culturais, educacionais e empresariais foram assinados. Fazendo referência apenas à última Cúpula realizada em 2008, IX Cúpula Brasil-Portugal, dois acordos foram assinados entre os governos dos dois países, para reforçar a concentração política e outro para criação de uma "linha direta" entre as autoridades da área de imigração e fronteiras, juntamente com outros dez acordos na área empresarial, dois deles firmados entre a Petrobras e a Galp e um deles entre a petrolífera brasileira e a EDP - Energias do Brasil. 
O envolvimento das autoridades portuguesas revela-se também na participação de membros do governo português em diversos acontecimentos de ordem empresarial e na forma como esse suporte é claramente expresso: "Outra condição necessária para as empresas portuguesas poderem aproveitar as oportunidades de negócio nos mercados internacionais tem a ver com a persecução, pelo Governo, de uma adequada política de diplomacia econômica. Muitas questões haverá também a considerar nesta matéria, entre as quais me permito sublinhar a ação permanente que o Governo e, designadamente, o meu Ministério, tem vindo a desenvolver no sentido de criar um bom relacionamento político com os governos dos países que consideramos mais relevantes para a internacionalização das empresas portuguesas, a realização de muitas missões de deslocação de membros do Governo acompanhadas por delegações empresariais a esses países e a divulgação e afirmação das competências portuguesas no plano internacional" (IPDAL, 2009).

A EDP foi uma das empresas que se beneficiou, desde o início, do impulso dado à internacionalização da economia portuguesa e cujo primeiro instrumento foram empresas com participação de capitais públicos. Esse é um fator que ainda hoje é relevante para a empresa, essencialmente para ganhar acesso, de forma estruturada, a informações sobre os países onde desenvolve as suas atividades.

\section{Nível Setorial}

\section{a) Regulação do setor elétrico}

Em suas publicações, a EDP relata que o principal fator político no ambiente externo setorial relevante para o processo de internacionalização foi a falta de definição de um quadro de regulação para o setor elétrico brasileiro mais justo e equitativo, que permitisse, de forma clara e inequívoca, uma melhoria dos níveis de retorno sobre o investimento realizado. Esse risco percebido pela EDP levou a empresa a reprogramar, em 2002, o desenvolvimento dos projetos das centrais hidroelétricas de Peixe Angical, como observado nas fases de entrada e consolidação referidas na Tabela 3. Em 2003 foi definido pelo governo brasileiro o novo enquadramento regulatório para o setor elétrico que, aliado a uma conjuntura macroeconômica favorável, transformaram um quadro de desproporcional percepção de risco para um de razoável equilíbrio, impulsionando a expansão da capacidade instalada neste mercado.

\section{b) Reajuste tarifário da Enersul}

Nos âmbitos organizacional e setorial, as relações desenvolvidas entre a EDP e as entidades brasileiras do setor elétrico desempenharam papel importante no reajuste tarifário da Enersul, controlada da EDP. Em 2003, a Agência Nacional de Energia Elétrica (Aneel) aprovou um reajuste de 42,26\% no valor da tarifa cobrada pela Enersul. O aumento foi considerado abusivo pelo Ministério Público Federal (MPF), pois teria gerado uma cobrança indevida de R $\$ 191,2$ milhões dos consumidores de energia elétrica de Mato Grosso do Sul desde 2003. O fato deu origem a uma Comissão Parlamentar de Inquérito (CPI). Esta CPI procurou encontrar indícios de ocorrência de crimes de estelionato, falsidade ideológica e contra economia popular, cometidos por diretores da Enersul e da Agência Nacional de Energia Elétrica (Aneel), devido ao reajuste tarifário realizado em 2003 e mostrou que o então superintendente de regulação da Aneel tornara-se diretor de regulação da Enersul alguns meses após o anúncio do aumento de preços.

\section{c) Patrocínio a magistrados}

Em 2006 foi noticiado o patrocínio parcial da Empresa Energética de Mato Grosso do Sul (Enersul) e da Associação Brasileira das Distribuidoras de Energia Elétrica (Abradee) no $10^{\circ}$ Encontro de Magistrados, evento em Bonito (CORREIO DO ESTADO MS, 2006), questionando-se a influência e interesse dessas empresas nos processos legais em curso. Ambas as instituições negaram as acusações, considerando que o 
fato de a Abradee ter patrocinado o encontro e o Judiciário ter suspenso um pedido de instalação de uma CPI da Enersul, na Assembleia Legislativa, foi uma "coincidência". "Nunca houve essa vinculação e não há agora. O que aconteceu, agora, foi pura coincidência, inclusive com relação à CPI da Enersul que não tem absolutamente nada a ver" (Marcelo Rasslan, presidente da Associação de Magistrados de Mato Grosso do Sul - Amamsul).

\section{Nível Organizacional}

\section{a) Conselho de Administração}

Em Setembro de 2005 foi definida a configuração do novo Conselho de Administração, após o ingresso da companhia no Novo Mercado da Bolsa de Valores de São Paulo, que foi alargado para nove membros, com a entrada de dois conselheiros independentes, porém com históricos de atuação no governo em cargos de relevância. Francisco Gros, que já tinha sido presidente do Banco Central, do BNDES e da Petrobras, e José Luiz Alquéres, ex-presidente da Eletrobrás, foram os membros escolhidos para o Conselho de Administração sem ligação a nenhum dos acionistas.

\section{b) Parceria com estatais}

A EDP estabeleceu com o grupo estatal Eletrobrás, por meio da Furnas Centrais Elétricas S.A. participada da Eletrobrás, um acordo para finalização da hidrelétrica Peixe Angical, que se encontrava parada por dificuldades de financiamento e relutância da EDP Portugal em financiar diretamente este projeto por incorrer em riscos cambiais. Através deste acordo, a Furnas comprometeu-se a adquirir uma participação de $40 \%$ neste projeto e o BNDES, banco de desenvolvimento do governo federal, assegurou o financiamento do projeto em cerca de 50\% (670 milhões de reais, para um orçamento total de 1391 milhões de reais) possibilitando uma redução substancial do esforço financeiro da EDP e permitindo que ela acessasse um recurso valioso no mercado brasileiro e cuja posse está largamente nas mãos do governo federal: financiamento de longo prazo.

A EDP Brasil estabeleceu em 2007 uma parceria com a Eletronorte, pertencente à estatal Eletrobrás, para projetos de construção de dois empreendimentos hídricos na região do Rio do Sono, em Tocantins. Este projeto teve um prazo inicial de conclusão previsto de 18 meses, após o qual é realizado um leilão público para a concessão dos empreendimentos. Em 2008, no âmbito da Cúpula Luso-Brasileira, a EDP Energias do Brasil assinou com a Petrobras um Memorando de Entendimento para a realização de estudos de projeto de geração a partir de usinas hidrelétricas, eólicas, biomassa e gás natural.

\section{Discussão}

A análise do caso da EDP revelou que fatores políticos em todos os três níveis estudados tiveram papel relevante para a consecução e viabilização do processo de internacionalização da empresa no Brasil. A EDP conseguiu vantagens competitivas, que alavancaram seus recursos e competências (aspectos baseados no mercado) e elevaram o seu nível de desempenho, ao utilizar as seguintes estratégias políticas: a) participação de políticos e do governo no board da empresa; b) parcerias com empresas locais para garantir o acesso a recursos controlados pelo governo; e c) aproximação com autoridades de poder decisório sobre o ambiente institucional da empresa. Essas três estratégias são comumente relatadas na literatura específica (HILLMAN e HITT, 1999) e fornecem recursos importantes para a internacionalização da empresa: acesso a recursos naturais e financeiros, legitimidade, informação privilegiada sobre a burocracia pública e futuras políticas públicas. 
Verifica-se ainda a importância do papel do estado português - enquanto diplomacia econômica - no desencadeamento da onda de investimento de empresas portuguesas para o Brasil, numa fase inicial de entrada no mercado. Porém, competências e recursos políticos existentes ao nível da empresa foram essenciais para ela se afirmar nas fases posteriores de consolidação, reorganização de portfólio e expansão autossustentável.

Conforme apresentado no início deste artigo, a literatura sobre estratégias políticas, ou non-market, procura explicar como as empresas desenvolvem mecanismos de acesso aos decisores políticos e influenciar o próprio processo político (HILLMAN, KEIM e SCHULER, 2004).

O contexto econômico dos países emergentes é ainda mais favorável ao aparecimento desse tipo de relações entre os meios político e econômico como exemplos, proteção individual (PEARCE, 2001), subornos em troca de favorecimentos e empresas multinacionais se beneficiando de condições de entrada especiais ao lidarem com governos tidos como corruptos (VAALER, 2008; RODRIGUEZ, UHLENBRUCK e EDEN, 2005; FRYNAS, MELLAHI e PIGMAN, 2006). Pesquisas realizadas com essas relações desenvolvidas entre empresas e governo revelaram um desempenho econômico superior por parte das empresas que utilizam estratégias políticas (PARK e LUO, 2001; PEARCE, 2001; FISMAN, 2001).

O caso específico do Brasil, assim como de diversos países em desenvolvimento, é particularmente favorável para o surgimento de fatores não baseados no mercado. Reformas de mercado em países em desenvolvimento possibilitaram o aparecimento de novas formas de renda a serem distribuídas pela classe política e estimularam a intensificação da concorrência entre políticos pelo acesso aos provedores de capital. Com a democratização dos sistemas políticos nesses países e consequente aumento de número de facções políticas, houve uma transferência do poder de negociação para a classe empresarial. A competição entre partidos rivais por rendas para financiamento das suas atividades permitiu maior abertura no acesso à classe política (MAXFIELD e SCHNEIDER, 1997).

O fim dos regimes autoritários na América Latina provocou a descentralização do poder político. O novo cenário político de regime democrático transformou radicalmente as relações existentes entre estado e empresas. No Brasil, em particular, os partidos políticos ficaram excessivamente fragmentados, fragilizados e conduzidos, muitas vezes, por motivações pessoais e individuais. Como exemplo, o Presidente Collor criou um novo partido para sua liderança pessoal com o fundamento de concorrer às eleições Presidenciais de 1989; e a coalizão liderada pelo Presidente Lula, para a sua reeleição era composta por dezessete partidos. Devido a esta fragmentação do sistema partidário é particularmente difícil formar maiorias quer na Câmara de Deputados, quer no Senado, conduzindo quase sempre o partido mais votado a negociar com outros partidos para formar maioria. Esse processo negocial tende a aumentar o processo burocrático e a favorecer meios alternativos para incremento das fontes de renda partidária. No Brasil, o poder executivo é responsável pela indicação de 20.000 posições em cargos públicos.

A organização associativista corporativa existente no Brasil, por si, também fomenta este tipo de relações entre empresas e o estado. A falta de associativismo corporativo (SCHNEIDER, 2004) capaz de controlar esse tipo de ações e influências individuais (MAXFIELD e SCHNEIDER, 1997) favorece o florescimento das estratégias políticas que procuram ganhos individuais oriundos das relações com o governo. As associações corporativas que existiam na década de 1930 foram consecutivamente sendo enfraquecidas pelos governos que subiram ao poder. Grupos industriais viram, por esta razão, o seu poder e influência política perder importância gradual (SCHNEIDER, 2004).

Estudos realizados por Claessens, Feijem e Laeven (2008) revelaram que as empresas com ligações, através de financiamentos de campanhas eleitorais, a deputados federais eleitos mostraram que estas empresas beneficiaram-se de acesso a recursos financeiros. A intervenção do governo brasileiro nos mercados financeiros pode ser vista como um instrumento para obtenção de apoio político em vez de ser usada para promover a redução de custos de transação (SAPIENZA, 2002; DINÇ, 2005), como comprova a história dos 
bancos sob controle do governo público (BAER, 2008), bem como a corrupção e ineficiência que se encontra no nível do sistema judiciário (LA PORTA et al., 1998).

\section{Conclusão}

A literatura sobre internacionalização de empresas tem se focado em argumentos baseados no mercado para explicar por que e como empresas atuam foram de seu mercado doméstico. Essas explicações incluem, por exemplo, a posse de ativos específicos, o ciclo de vida dos produtos, e o valor de competências adquiridas com a experiência em internacionalização. Estudos que abordam o ambiente institucional não mercadológico, mais especificamente, o ambiente político, são apenas marginais. Apesar de sempre presente nos fenômenos relacionados à internacionalização de empresas, o aumento do papel dos governos como resultado das frustradas experiências neoliberais na década de noventa, principalmente em países em desenvolvimento, traz à tona novamente a importância da atuação política das empresas nas diversas fases do processo de internacionalização.

As condições pelas quais a Energias de Portugal (EDP) se internacionalizou no Brasil propiciaram condições favoráveis para avançar tanto teórica como empiricamente sobre o papel dos percursos políticos. Primeiro, o caso permitiu analisar o processo nas suas diversas fases, entrada, consolidação, reorganização do portfólio, e expansão, e em diferentes níveis, organizacional, setorial e nacional. A partir de dados secundários triangulados em diversas fontes, os resultados dessa análise processual e multinível geram interessantes insights e contribuições.

Este estudo faz, portanto, três contribuições para complementação das teorias sobre internacionalização, ao permitir concluir que: a) a posse de capacidades e recursos técnicos e de know-how necessários à entrada e consolidação foram condições necessárias, mas não suficientes para viabilizar o processo de internacionalização da EDP no Brasil. Os fatores políticos desempenharam um papel relevante para tornar possível a implementação do negócio; b) as empresas estatais foram importantes fornecedores de recursos políticos, o que reforça a importância, encontrada na literatura, de parcerias com empresas locais, mas, neste caso, empresas ligadas ao governo hospedeiro; e c) a história da EDP no Brasil representa um caso de empresa oriunda de um país com estabilidade institucional que desenvolveu capacidades para lidar com o ambiente político e mitigar o risco. Esse caso contradiz em parte achados recentes da literatura de negócios internacionais que mostram que empresas de países que apresentam maiores facilidades institucionais para a distribuição de rendas políticas têm maior habilidade para lidar com os riscos políticos nos países hospedeiros (HOLBURN e ZELNER, 2010). A EDP mostrou que, em vez de trazer essas capacidades de seu país de origem, ela conseguiu desenvolver essas capacidades políticas ao longo de sua atuação no Brasil.

Limitações fazem parte de todo trabalho científico. Nesta pesquisa, a principal limitação consiste-se da sensibilidade do fenômeno da atuação político, o que dificulta a coleta de dados primários. Entrevistas com dirigentes da empresa poderiam servir como fontes de novas descobertas e caminhos para interpretação, apesar de naturalmente conter viéses. Mas poderiam servir de mais base para triangulação com os dados secundários.

Estudos futuros poderiam explorar com maior profundidade a interação entre os três níveis analisados. É importante tanto para acadêmicos como para gestores identificar os mecanismos pelos quais os três níveis interagem entre si para melhor isolar os seus efeitos e decidir sobre os investimentos em atuação política. Finalmente, este estudo contribui para uma melhor compreensão do processo de internacionalização de empresas portuguesas para o Brasil, tema que tem despertado o interesse de pesquisadores de ambos os países ao longo das últimas décadas. 


\section{Referências}

BAER, W. The brazilian economy. Londres: Lynne Rienner, 2008.

BARNEY, J. Firm resources and sustained competitive advantage. Journal of Management, v. 17, n. 1, p. 99-120, 1991.

BARON, D. P. Integrated Strategy and International Trade Disputes: The Kodak-Fujifilm Case. Journal of Economics \& Management Strategy, v. 6, n. 2, p. 291-346, 1997.

BLUMENTRITT, T. P.; NIGH, D. The integration of subsidiary political activities in multinational corporations. Journal of International Business Studies, v. 33, n. 4, p. 57-77, 2002.

BODDEWYN, J. J. Political aspects of MNE theory. Journal of International Business Studies, v.19, n. 3, p. 341363, 1998.

; BREWER, T. L. International-Business Political Behavior: New Theoretical Directions. Academy of Management Review, v. 19, n. 1, p. 119-143, 1994.

BONARDI, J.; HILLMAN, A.; KEIM, G. The attractiveness of political markets: implications for firm strategy. Academy of Management Review, v. 30, n. 2, p. 397-413, 2005.

.; HOLBURN, G. L. F.; VANDEN Bergh, R. G. Nonmarket strategy performance: evidence from U.S. electric utilities. Academy of Management Journal, v. 49, n. 6, p. 1209-1228, 2006.

BUCKLEY, P.; CASSON, M. The future of the multinational enterprise. London: Macmillan, 1976.

CAVES, R. International corporations: the industrial economics of foreign investment. Economica, v. 38 , n. 149 (February), p. 1-27, 1971.

CLAESSENS,S.; FEIJEN, E.; LAEVEN, L. Political connections and preferential access to finance: the role of campaign contributions. Journal of Financial Economics, v. 88, n.33, p. 554-580, 2008.

COASE, R. The Nature of the Firm. Economica, v. 4, n. 16, p. 386-405, 1937.

DINÇ, I. S. Politicians and banks: political influences on government-owned banks in emerging markets. Journal of Financial Economics, v. 77, p. 453-479, 2005

DUNNING, J. The eclectic paradigm of international production: a restatement and some possible extensions. Journal of International Business Studies, v.19, n. 1 (march), p.1-31, 1988.

EISENHARDT, K. M. Building theories from case study research. Academy of Management Review, v.14, n. 4, p. 532-550, 1989.

.; GRAEBNER, M. Theory building from cases: opportunities and challenges. Academy of Management Journal, v. 50, n. 2, p. 25-32, 2007.

FERNANDES, F. R. C.; SILVA, J. R.; COSTA, C. G. Empresas e subsidiárias portuguesas no Brasil: um panorama. Prospectiva e Planeamento do Investimento Português no Estrangeiro, 9 (ño especial), p. 97-121, 2003.

Os investimentos portugueses no Brasil. Lisboa: Icep, 2005.

FISMAN, R. Estimating the value of political connections. The American Economic Review, v. 91, n. 4, p. 1095$1102,2001$. 
FRYNAS, J. G.; MELLAHI, K.; PIGMAN, G. A. First Mover Advantages in International Business and Firm Specific Political Resources. Strategic Management Journal, v. 27, n. 3, p. 321-345, 2006.

HENISZ, W. J. The Institutional Environment for Multinational Investment. Journal of Law, Economics and Organization, v. 16, n.2, p. 334-364, 2000.

The power or the Buckley and Casson thesis: the ability to manage institutional idiosyncrasies. Journal of International Business Studies, v. 34, n. 2, p. 173-184, 2003.

; WILLIANSON. O. E. Comparative Economic Organization: Within and Between Countries. Business and Politics, v. 1, n. 3, p. 261-77, 1999.

HILLMAN, A. Politicians on the board of directors: do connections affect the bottom line? Journal of Management, v. 31, n. 3, p. 464-481, 2005.

; HITT, M. A. Corporate political strategy formulation: a model of approach, participation, and strategy decisions. Academy of Management Review, v. 24, n. 4, p. 825-842, 1999.

.; KEIM, G. International variation in the business-government interface: institutional and organizational considerations. The Academy of Management Review, v. 20, n. 1, p. 193-214, 1995.

.; ___ _ SCHULER, D. Corporate political activity: a review and research agenda. Journal of Management, v. 30, n. 6, p. 837-857, 2004.

.; WAN, W. P. The determinants of MNE subsidiaries' political strategies: evidence of institutional duality. Journal of International Business Studies, v. 36, n. 3, p. 322-340, 2005.

HYMER, E. The international operations of national firms: a study of direct foreign investment. Cambridge: MIT Press, 1960.

HOLBURN, G.; ZELNER B. Political Capabilities, Policy Risk, and International Investment Strategy: Evidence from the Global Electric Power Generation Industry. Strategic Management Journal, 31; p. 1290-1315, 2010.

IPDAL. Discurso do Ministro de Obras Públicas de Portugal no Fórum Oportunidades de Negócio na América Latina de 2009. http://www.ipdal.org/index.php?option=com_content\&task=view\&id=216\&Itemid=51.

JOHANSON, B.; VAHLNE, J. The internacionalization process of the firm: a model of knowledge development and increasing foreign market commitments. Journal of International Business Studies, Basingstoke, v.8, n.1, p.23-32, 1977.

KEIM, G. D.; ZEITHALM, C. P. Corporate political strategy and legislative decision making: a review and contingency approach. Academy of Management Review, v. 11, n. 4, p.828-843, 1986.

.; ZEITHALM, C. P.; BAYSINGER, B. D. New directions for corporate political strategy. Sloan Management Review, v. 25, n. 3, p. 53-62, 1984.

LAPORTA, R.; LOPEZ-DE-SILANES, F.; SHLEIFER, A.; VISHNY, R. Law and Finance. Journal of Political Economy, v. 106, n. 06, p. 1113-1155, 1998.

LENWAY, S. A.; REHBEIN, K. Leaders, followers, and free riders: an empirical test of variation in corporate political involvement. Academy of Management Journal, v. 34, n. 4, p. 893-905, 1991.

LESTER, R.; HILLMAN, A.; ZARDKOOHI, A.; CANNELLA JR., A. Former government officials as outside directors: the role of human and social capital. Academy of Management Journal, v. 51, n. 5, p. 999-1013, 2008.

LUO, Y. Political behavior, social responsibility, and perceived corruption: a structuration perspective. Journal of International Business Studies, v. 37, n. 6, p. 747-766, 2006. 
MAXFIELD, S.; SCHNEIDER, B. R. Business and the state in developing countries. New York : Cornell University Press, 1997.

MCWILLIANS, A.; VAN FLEET, D. D.; CORY, K. D. Raising rivals' costs through political strategy: an extension of resource-based theory. Journal of Management Studies, v. 39, n. 5, p. 707- 723, 2002.

PARK, S. H. LUO, Y. Guanxi and organizational dynamics: organizational networking in Chinese firms. Strategic Management Journal, v. 22, p. 455-477, 2001.

PEARCE, J. Organization and management in the embrace of government. Mahwah, New Jersey: LEA, 2001.

PENG, M.; HEATH, P. The growth of the firm in planned economies in transition: institutions, organizations, and strategic choice. Academy of Management Journal, v. 21, n. 2, p. 491-528, 1996.

PENROSE, E. The theory of growth of the firm. 2. ed. New York: Oxford, 1959.

PORTER, M. The Competitive Advantage of Nations. Free Press: New York, 1990.

RING, P. S.; LENWAY, S. A.; GOVEKAR, M. Management of the Political Imperative in International Business. Strategic Management Journal, v. 11, n. 2, p. 141-151, 1990.

RODRIGUEZ, P.; UHLENBRUCK, K.; EDEN, L. Government corruption and the entry strategies of multinationals. Academy of Management Review, v. 30, n. 2, p. 383-396, 2005.

SAPIENZA, P. What do State-owned firms maximize? Evidence from Italians banks. Centre for Economic Policy Research, 3168, 2002.

SCHNEIDER, B. R. Business politics and the State in twentieth-centuri Latin America. Cambridge: Cambridge University Press, 2004.

SCHULER, D. A. Corporate political strategy and foreign competition: the case of the steel industry. Academy of Management Journal, v. 39, n. 3, p. 720-737, 1996.

.; REHBEIN, K.; CRAMER, R. Pursuing strategic advantage through political means: a multivariate approach. Academy of Management Journal, v. 45, n. 4, p. 659-672, 2002.

SHAFFER, B. Firm-level responses to government regulation: theoretical and research approaches. Journal of Management, 21, n. 3, p. 495-514, 1995.

SIGARDO, P. Apresentação do diretor do Instituto EDP. http://www.slideshare.net/ambienteenergia/edp-pedro-sirgado.

SILVA, J. R. A internacionalização das empresas portuguesas: a experiência brasileira. Revista de Administração de Empresas, 45 (edição especial), p. 102-115, 2005.

SUN, P. MELLAHI, K. THUN, E. The dynamic value of MNE political embeddedness: The case of the Chinese automobile industry. Journal of International Business Studies, v. 41, n. 1, p. 1161-1182, 2010.

VAALER, P. M. How do MNCs vote in developing country elections? Academy of Management Journal, v. 51, n. 1, p. 21-43, 2008.

VERNON, R. International investments and international trade in the product cycle. Quarterly Journal of Economics, v.80, n.2, p. 190-207, 1966.

WAN, W. Country resource environments, firm capabilities, and corporate diversification strategies. Journal of Management Studies, v. 42, n. 1, p. 161-182, 2005. 
WEYLAND, K. The politics of market reform in fragile democracies. Woodstock: Princeton University Press, 2002.

WILLIAMSON, O. The economic institutions of capitalism. New York: Free Press, 1985.

YIN, R. K. Estudos de caso: planejamento e métodos. Porto Alegre: Bookman, 2005.

ZANnI, P. P. MORAES, G. H. S. M. MARIOTTO, F. L. Para que servem os Estudos de Caso Único? XXXV Encontro Nacional de Pós- Graduação em Administração (ENANPAD). Anais. 2011. 
Anexo 1

\section{Quadro cronológico das atividades da EDP no Brasil}

\begin{tabular}{|c|c|}
\hline ANO & Principais Atividades \\
\hline 1996 & $\begin{array}{l}\text { Compra de } 21 \% \text { da CERJ (Distribuidora no Rio de Janeiro) - Início das operações do Grupo EDP, com a } \\
\text { aquisição de uma participação minoritária na CERJ (hoje Ampla) }\end{array}$ \\
\hline 1997 & $\begin{array}{l}\text { O Grupo EDP assume } 25 \% \text { da hidroelétrica Luis Eduardo Magalhães (Lajeado), no Tocantins, } \\
\text { realizando assim seu primeiro investimento na área de geração no país. }\end{array}$ \\
\hline 1998 & $\begin{array}{l}\text { Aquisição de } 17 \% \text { da Bandeirante - Aquisição da Bandeirante Energia, em conjunto com a CPFL, no } \\
\text { âmbito do processo de desestatização do setor elétrico paulista }\end{array}$ \\
\hline 1999 & $\begin{array}{l}\text { Aquisição de participação direta e indireta na Iven, veículo controlador da Escelsa e Enersul e criação } \\
\text { da EDP Brasil }\end{array}$ \\
\hline 2001 & $\begin{array}{l}\text { OPA e cisão da Bandeirante - Cisão da Bandeirante Energia, com a saída da CPFL do capital social da } \\
\text { empresa, que passa a ser controlada unicamente pela EDP Brasil. Aquisição de } 95 \% \text { do projeto hídrico } \\
\text { Peixe-Angical - Aquisição em leilão da concessão para construir a usina no Tocantins. Início da Fafen } \\
\text { (Central termoelétrica na Bahia) - Início da construção da termoelétrica fafen, no polo petroquímico } \\
\text { de Camaçari (BA) em parceria com a Petrobras. }\end{array}$ \\
\hline 2003 & $\begin{array}{l}\text { Parceria com Furnas em Peixe Angical - Retomada das obras que passa a ter a Furnas como sócia } \\
\text { (40\%) na Enerpeixe,com financiamento do BNDES e de um pool de bancos. Como primeiro passo de } \\
\text { sua reestruturação societária, a então EDP Brasil passa a ter controle direto da Iven SA e } \\
\text { consequentemente da Escelsa e Enersul. Com o objetivo de um maior enfoque de recursos e } \\
\text { capacidades de gestão no mercado brasileiro, definido como prioritário. }\end{array}$ \\
\hline 2004 & $\begin{array}{l}\text { Venda da Fafen para a Petrobras - como efeito da ausência de um ambiente regulatório adequado } \\
\text { para as usinas termoelétricas. Começa o programa Eficiência - projeto de sinergias nas distribuidoras. } \\
\text { Segunda fase de reestruturação societária que prepara a migração dos acionistas minoritários das } \\
\text { distribuidoras. }\end{array}$ \\
\hline 2005 & $\begin{array}{l}\text { Conclusão do processo de reestruturação societária - Desverticalização dos ativos, com a segregação } \\
\text { dos negócios de geração e distribuição. Lançamento da identidade visual baseada no sorriso, em } \\
\text { consonância com o acionista controlador em Portugal, e mudança de nome para EDP do Brasil. IPO da } \\
\text { EDP do Brasil - Abertura do capital da companhia com oferta pública de ações no novo mercado da } \\
\text { BM\&F Bovespa e capitalização das dívidas em dólar da Escelsa. EDP do Brasil define novo Conselho de } \\
\text { Administração 2005, configuração foi alargada para nove membros com a entrada de dois } \\
\text { conselheiros independentes. }\end{array}$ \\
\hline 2006 & $\begin{array}{l}\text { Entrada em funcionamento de peixe Angical - Conclusão das obras do aproveitamento hídrico Peixe } \\
\text { Angical no Tocantins. Ações da EDP Brasil ingressam no ISE, Índice de Sustentabilidade Empresarial da } \\
\text { Bovespa }\end{array}$ \\
\hline 2007 & $\begin{array}{l}\text { Investimento numa central a carvão - Aquisição da usina termoelétrica Pecem, no Maranhão, em } \\
\text { parceria com a MPX Mineração. Cada empresa detém 50\% do empreendimento. }\end{array}$ \\
\hline
\end{tabular}

Fonte: Elaborado pelos autores. 